\title{
Effects of calcium supplementation on bone density in healthy children: meta-analysis of randomised controlled trials
}

Tania Winzenberg, Kelly Shaw, Jayne Fryer, Graeme Jones

\begin{abstract}
Objectives To assess the effectiveness of calcium supplementation for improving bone mineral density in healthy children and to determine if any effect is modified by other factors and persists after supplementation stops.

Design Meta-analysis.

Data sources Electronic bibliographic databases, hand searching of conference proceedings, and contacting authors for unpublished data.

Review methods We included randomised placebo controlled trials of calcium supplementation in healthy children that lasted at least three months and had bone outcomes measured after at least six months of follow-up. Two reviewers independently extracted data and assessed quality. Meta-analyses predominantly used fixed effects models with outcomes given as standardised mean differences.

Results We included 19 studies involving 2859 children. Calcium supplementation had no effect on bone mineral density at the femoral neck or lumbar spine. There was a small effect on total body bone mineral content (standardised mean difference $0.14,95 \%$ confidence interval 0.01 to 0.27 ) and upper limb bone mineral density $(0.14,0.04$ to 0.24$)$. This effect persisted after the end of supplementation only at the upper limb $(0.14,0.01$ to 0.28$)$. There was no evidence that sex, baseline calcium intake, pubertal stage, ethnicity, or level of physical activity modified the effect.

Conclusions The small effect of calcium supplementation on bone mineral density in the upper limb is unlikely to reduce the risk of fracture, either in childhood or later life, to a degree of major public health importance.
\end{abstract}

\section{Introduction}

Osteoporosis is a major public health problem, particularly in women. ${ }^{1-3}$ Low bone mineral density is an important risk factor for osteoporotic fracture. ${ }^{4}$ At least $90 \%$ of peak bone mass (the maximum bone mass attained by an individual) is obtained by the age of $18 . .^{5}$ Postmenopausal bone mineral density is a function of peak bone mass and the rate of subsequent bone loss, ${ }^{6}$ which are equally important risk factors for fracture in later life. $^{7}$ Thus, intervention in childhood to maximise peak bone mass by improving modifiable factors such as diet and physical activity ${ }^{8}$ might minimise the impact of bone loss related to age. As low bone mineral density is a risk factor for fracture in childhood, ${ }^{9-11}$ optimising age appropriate bone mass may also have a more immediate beneficial effect.

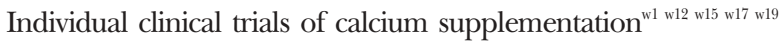
and dairy products ${ }^{12}$ have shown increases in bone mineral den- sity in children, although the increases may not be maintained. ${ }^{\mathrm{w} 15}$ Narrative reviews have concluded that overall calcium supplementation seems to have a modestly favourable effect on bone outcomes at the end of the treatment period..$^{13-15}$

We carried out a quantitative systematic review to determine the effectiveness of calcium supplementation for improving bone mineral density in healthy children; if any effect varies by sex, baseline calcium intake, pubertal stage, ethnicity, or level of physical activity; and whether any effect persists after calcium supplementation stops.

\section{Methods}

Detailed description of the review methods is available elsewhere ${ }^{16}$ Briefly, we included studies if they were randomised controlled trials of calcium supplementation (including in food) compared with placebo, with a treatment period of at least three months; participants were children (age $<18$ ) without coexisting medical conditions or treatments affecting bone metabolism; outcome measures included areal or volumetric bone mineral density, bone mineral content, broadband ultrasound attenuation, or speed of sound measured at any site; and bone outcomes were measured after at least six months of follow-up.

We applied the search strategies (see bmj.com for details) to the following electronic bibliographic databases: CENTRAL, (Cochrane Central Register of Controlled Trials) (issue 3, 2005), Medline (1966 to 1 April 2005), Embase (to 1 April 2005), CINAHL (1982 to 1 April 2005), AMED (1985 to 1 April 2005), MANTIS (1980 to 1 April 2005), ISI Web of Science (1945 to 1 April 2005), Food Science and Technology Abstracts (1969 to 1 April 2005), and Human Nutrition (1982 to 1 April 2005). We also hand searched conference abstract books (Osteoporosis International 1990-9, Journal of Bone and Mineral Research 2002-3).

Two reviewers (TW and KS) independently assessed articles for inclusion, extracted data, and assessed quality. Quality assessment included assessment of randomisation, allocation concealment, blinding, and description of withdrawals and dropouts and was used to give an overall rating of the risk of bias. ${ }^{17} 18$

In the absence of trials in children with fracture as an outcome, we used bone mineral density, bone mineral content, broadband ultrasound attenuation, and speed of sound as outcomes measures. These outcomes measured at any site were all considered a priori primary outcomes, but their inclusion in the analysis depended on the availability of adequate data. We had data for total body bone mineral density and for density at

A list of references for the included studies (w1-w35) and the search strategy can be found on bmj.com. 


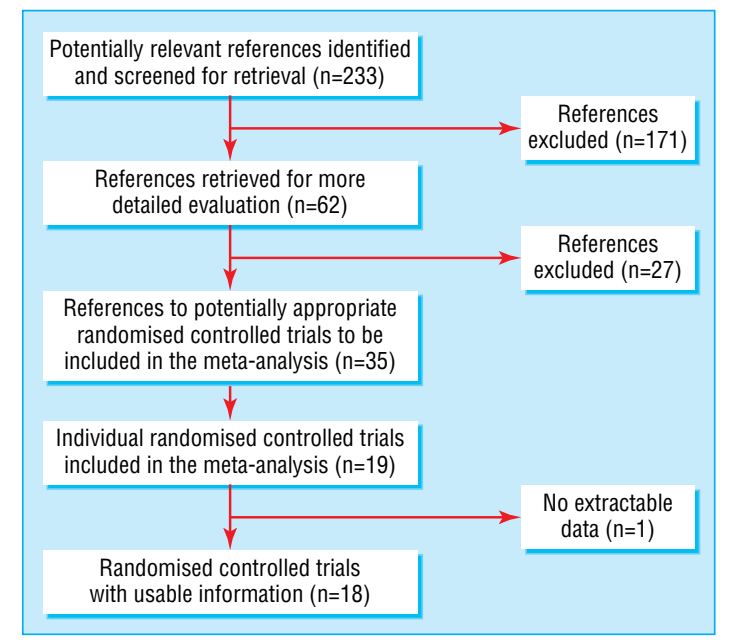

Fig 1 Flow of studies through the review

the femoral neck, lumbar spine, distal radius, and upper limb (defined as the distal radius or the upper limb site closest to that point). We used endpoint data rather than change data to maximise data availability.

We converted outcome measures to standardised mean differences using RevMan version 4.2.7. We assessed heterogeneity of the data with a $\chi^{2}$ test and conducted a meta-analysis according to a fixed effects model for the main effect outcomes. Where there was heterogeneity in subgroup analyses we used random effects models.

Subgroup analyses were performed for sex, baseline calcium intake, pubertal stage, ethnicity, physical activity, type of supplementation (milk extract compared with other calcium supplement forms), and duration of supplementation. The median mean baseline calcium intake for each study (794 $\mathrm{mg} /$ day) was used as the cut-off for calcium intake subgroups. We had sufficient studies to also perform this analysis using a lower cut-off (25th centile, $582 \mathrm{mg}$ /day) for upper limb bone mineral density. For the physical activity analysis, where physical activity was a cointervention or subgroup in a study, we included those in the low physical activity arm in the low physical activity subgroup for the meta-analysis and those in the high physical activity arm in the high physical activity subgroup. We chose a cut point of 18 months for the study duration subgroups, so as to have exceeded the bone remodelling transient. We also performed a subgroup analysis by whether the calcium intake in the intervention group in the trial exceeded the probable threshold (1400 mg/day) below which skeletal accumulation varies with intake and above which skeletal accumulation seems constant regardless of intake. ${ }^{19} 20$

We collected data on adverse effects, where available. When necessary we contacted the authors of the primary studies to obtain additional information.

We used intention to treat data from trials wherever possible. If these were not available, we used data from the analysis of available data or, if no other data were available, data from the analysis of treatment received. For the single study in which upper limb outcomes were presented as percentage change from baseline, and no endpoint data were available, ${ }^{\text {w35 }}$ we imputed endpoint data using the baseline bone mineral density and percentage change from baseline and the standard deviation (SD) of the baseline data for the endpoint SD. Where studies reported absolute change from baseline and endpoint data were not available $^{\mathrm{w1} \text { w7 w11 w19 w33 }}$ we imputed endpoints using baseline plus change for the mean and using the SD of the baseline data for the endpoint SD. We performed a sensitivity analysis for the main effects omitting studies for which data were

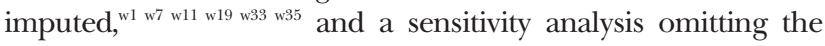
study $^{\mathrm{w1}}$ that reported results only from analysis of treatment received.

Table 1 Characteristics of included studies

\begin{tabular}{|c|c|c|c|c|c|c|c|c|}
\hline Study & $\begin{array}{l}\text { Supplement and Ca dose } \\
\text { (mg/day) }\end{array}$ & $\begin{array}{c}\text { Duration of } \\
\text { supplement/ } \\
\text { follow-up (years) }\end{array}$ & No* & $\begin{array}{l}\text { Ethnicity/pubertal } \\
\text { stage }\end{array}$ & $\begin{array}{c}\text { Female } \\
(\%)\end{array}$ & $\begin{array}{l}\text { Mean (range) } \\
\text { age (years) }\end{array}$ & $\begin{array}{l}\text { Baseline Ca† } \\
\text { (mg/day) }\end{array}$ & Sites measured \\
\hline Bonjour 1995 w1-5 & Milk extract, 850 & $1 / 8$ & 149 & White/prepubertal & 100 & $7.93(6.6-9.4)$ & 752 & Radius, hip, LS \\
\hline Cameron 2004 & $\mathrm{CaCO}_{3}, 1200$ & $2 / 2$ & 128 & NS/prepubertal & 100 & $10.3(8-13)$ & 716 & Hip, forearm, LS, TB \\
\hline Chevalley $2005^{\mathrm{w} 7}$ & Milk extract, 850 & $1 / 2$ & 235 & White/prepubertal & 0 & $7.44(6.5-8.5)$ & 752 & Radius, hip, LS, TB \\
\hline Courteix $2005^{\mathrm{w} 8}$ & $\mathrm{CaPO}_{4}, 800$ & $1 / 1$ & 113 & White/prepubertal & 100 & $9.91(8-13)$ & 994 & Radius, hip, LS, TB \\
\hline Dibba $2000^{\mathrm{wg}-10}$ & $\mathrm{CaCO}_{3}, 1000 \mathrm{mg} 5$ days/week & $1 / 3$ & 160 & Gambian/mixed & 50 & $10.3(8.3-11.9)$ & 338 & Radius \\
\hline Iuliano-Burns 2003 ${ }^{\text {w11 }}$ & $\begin{array}{l}\text { Foods fortified by milk } \\
\text { minerals, } 400\end{array}$ & $0.7 / 0.7$ & 72 & $\begin{array}{l}\text { Asian } 15 \% \text {, rest NS; } \\
85 \%, 80 \% \text { prepubertal }\end{array}$ & 100 & $8.86(7-11)$ & 674 & $\begin{array}{l}\text { TB, upper and lower } \\
\text { limb, LS }\end{array}$ \\
\hline Johnston $1992^{12-14}$ & CaCM, 1000 & $3 / 6$ & 140 & White/mixed & 61 & $10(6-14)$ & 919 & Radius, hip, LS \\
\hline Lee 1994w15 w16 & $\mathrm{CaCO}_{3}, 300$ & $1.5 / 2.5$ & 163 & Chinese/prepubertal & 46 & 7.18 (NS) & 277 & Radius \\
\hline Lee $1995^{w 17}$ w18 & $\mathrm{CaCO}_{3}, 300$ & $1.5 / 3$ & 109 & Chinese/prepubertal & 43 & Age7 & 567 & Radius, hip, LS \\
\hline Lloyd 1993 w19-w22 & CaCM, 500 & $2 / 2$ & 112 & White/mixed & 100 & 11.9 (NS) & 976 & Pelvis, LS, TB \\
\hline Matkovic $2004^{\text {w23-26 }}$ & CaCM, 1000 & $7 / 7$ & 354 & White/peripubertal & 100 & 10.8 (NS) & 837 & Radius, TB \\
\hline Molgaard 2004 $4^{\text {w27 }}$ & $\mathrm{CaCO}_{3}, 300$ & $1 / 2$ & 113 & White/mixed & 100 & $13.2(12-14)$ & 841 & TB \\
\hline Nowson $1997^{\text {w28 }}$ & $\begin{array}{l}\mathrm{CaCO}_{3} / \mathrm{Ca} \text { lactate gluconate, } \\
1000\end{array}$ & $1.5 / 1.5$ & 110 & NS/mixed & 100 & $14(10-17)$ & 734 & Forearm, hip, LS, TB \\
\hline Prentice $2005^{\mathrm{w} 29}$ & $\mathrm{CaCO}_{3}, 1000$ & $1 / 1$ & 150 & White/postpubertal & 0 & $16.8(16-18)$ & 1198 & Radius, hip, TB \\
\hline Rodda $2004^{\text {w30 }}$ & $\mathrm{CaCO}_{3}, 1200$ & $1-4 / 4$ & 93 & $\begin{array}{l}\text { Chinese } 43 \% \text {, white } \\
57 \% / \mathrm{NS}\end{array}$ & 100 & N.S. $(10-12)$ & NS & TB, LS \\
\hline Rozen $2003^{\text {w31-32 }}$ & $\mathrm{CaCO}_{3}, 1000$ & $1 / 4.5$ & 112 & $\begin{array}{l}\text { Jewish } 76 \% \text {, Arab } \\
24 \% / \text { postpubertal }\end{array}$ & 100 & $14.85(12-17)$ & 582 & Hip, LS, TB \\
\hline Specker $2003^{\text {w33 }}$ & $\mathrm{CaCO}_{3}, 1000$ & $1 / 1$ & 239 & White/prepubertal & 47 & $3.92(3-5)$ & 946 & TB, arm, leg \\
\hline Stear $2003^{\mathrm{w} 34}$ & $\mathrm{CaCO}_{3}, 1000$ & $1.3 / 1.3$ & 144 & NS/post pubertal & 100 & $17.3(16-18)$ & 938 & Radius, hip, LS, TB \\
\hline Wang 1996"w35 & $\mathrm{CaCO}_{3}, 300$ & $1.5 / 1.5$ & 163 & Chinese/prepubertal & 46 & 7.2 (NS) & 277 & Radius \\
\hline
\end{tabular}

$\mathrm{CaCO}_{3}=$ calcium carbonate; $\mathrm{Ca}=$ calcium; $\mathrm{CaCM}=$ calcium citrate malate; $\mathrm{CaPO}_{4}=$ calcium phosphate; $\mathrm{LS}=$ lumbar spine; $\mathrm{TB}=$ total body; NS=not stated

*Number of subjects randomised.

†Mean baseline calcium intake. 


\begin{tabular}{|c|c|c|c|c|c|c|c|}
\hline & N & $\begin{array}{l}\text { Treatment } \\
\text { mean (SD) }\end{array}$ & N & $\begin{array}{c}\text { Control } \\
\text { mean (SD) }\end{array}$ & $\begin{array}{c}\text { SMD (fixed) } \\
(95 \% \text { CI })\end{array}$ & $\begin{array}{c}\text { Weight } \\
(\%)\end{array}$ & $\begin{array}{l}\text { SMD (fixed) } \\
(95 \% \text { CI })\end{array}$ \\
\hline \multicolumn{8}{|c|}{ At end of supplementation (all data) } \\
\hline Johnston 1992 & 45 & $317.09(69.40)$ & 45 & $311.51(69.67)$ & & 5.81 & $0.08(-0.33$ to 0.49$)$ \\
\hline Lee 1994 & 77 & $487.00(41.00)$ & 82 & $480.00(43.00)$ & & 10.22 & $0.17(-0.15$ to 0.48$)$ \\
\hline Bonjour 1995 & 55 & $312.00(29.66)$ & 53 & $308.00(29.12)$ & 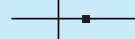 & 6.96 & $0.14(-0.24$ to 0.51$)$ \\
\hline Lee 1995 & 44 & $492.00(39.00)$ & 40 & $491.00(51.00)$ & & 5.41 & $0.02(-0.41$ to 0.45$)$ \\
\hline Wang 1996 & 79 & $486.00(37.00)$ & 83 & $479.00(31.00)$ & & 10.40 & $0.20(-0.10$ to 0.51$)$ \\
\hline Dibba 2000 & 80 & $253.00(50.00)$ & 80 & $231.00(50.00)$ & & 10.09 & $0.44(0.12$ to 0.75$)$ \\
\hline Stear 2003 & 65 & $427.00(38.00)$ & 66 & $418.00(43.00)$ & & 8.41 & $0.22(-0.12$ to 0.56$)$ \\
\hline Cameron 2004 & 24 & $418.00(43.00)$ & 24 & $414.00(42.00)$ & & 3.10 & $0.09(-0.47$ to 0.66$)$ \\
\hline Matkovic 2004 & 79 & $450.00(53.00)$ & 98 & $438.00(50.00)$ & . & 11.22 & $0.23(-0.06$ to 0.53$)$ \\
\hline Chevalley 2005 & 114 & $309.60(28.00)$ & 118 & $308.20(32.00)$ & 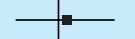 & 14.97 & $0.05(-0.21$ to 0.30$)$ \\
\hline Courteix 2005 & 22 & $336.18(43.19)$ & 63 & $351.00(69.75)$ & & 4.19 & $-0.23(-0.72$ to 0.26$)$ \\
\hline Prentice 2005 & 73 & $479.00(61.00)$ & 70 & $482.00(51.00)$ & & 9.23 & $-0.05(-0.38$ to 0.27$)$ \\
\hline Total $(95 \%$ Cl) & 757 & & 822 & & $<$ & 100.00 & 0.14 (0.04 to 0.24$)$ \\
\hline
\end{tabular}

Test for overall effect: $z=2.71, P=0.007$

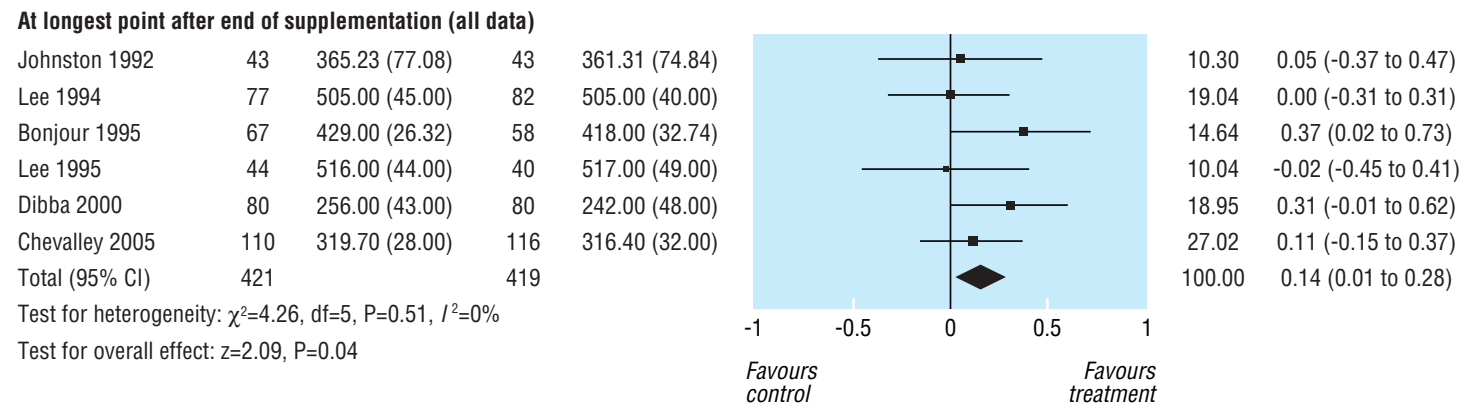

Fig 2 Effect of calcium supplementation on bone mineral density at the upper limb at the end of trial and at the longest point after supplementation stopped (SMD=standarised mean difference)

To aid in the assessment of the clinical relevance of the results, we used the standardised mean difference to estimate an absolute benefit in $\mathrm{mg} / \mathrm{cm}^{2} .{ }^{21}$ We then estimated the relative difference in the change from baseline as the absolute benefit divided by the mean of all the baseline means of the control groups, expressed as a percentage. We used funnel plots to assess publication bias.

\section{Results}

We identified 233 references to potential studies. We included 35 references to 19 randomised controlled trials involving 2859 participants, aged 3-18 years, in the systematic review (see fig 1). The list of excluded studies and reasons for exclusion are given elsewhere ${ }^{16}$ Of the 2859 participants, 1367 were randomised to receive calcium supplementation and 1426 to placebo. Sixty six participants withdrew from studies without their treatment allocation being reported.

Table 1 summarises the characteristics of included studies (references ${ }^{\mathrm{w} 1 \mathrm{w} 35}$ are on bmj.com). Calcium supplementation was with a calcium dose of 300-1200 mg per day from calcium citrate malate, calcium carbonate, calcium phosphate, calcium lactate gluconate, calcium phosphate milk extract, or milk minerals. No studies that used dairy foods as a supplement met the inclusion criteria. One study used intention to treat analysis ${ }^{\mathrm{w} 9}$; in one study the type of analysis was not stated ${ }^{\mathrm{w} 30}$; in one study ${ }^{\mathrm{w} 1}$ only data from analysis of treatment received were available for outcomes at end of trial. The remaining studies reported results from analysis of available data.

A full description of the methodological quality of included studies is given elsewhere. ${ }^{16}$ Overall, we rated the risk of bias as low in two studies, ${ }^{\text {w8 }}{ }^{\mathrm{w} 9}$ moderate in 12 studies, ${ }^{\text {w1 }}$ w6 w7 w12 w15 w17 w19 w27 w28 w29 w30 w33 and high in five studies. ${ }^{\text {w11 w25 w31 w34 w35 }}$

Table 2 gives the treatment effects at each site at the end of supplementation and after the longest period of follow-up available after supplementation stopped for each trial. Results for the distal radius are not reported separately as they were similar to those for the upper limb. There was no effect of calcium supplementation on bone mineral density at the femoral neck

Table 2 Main effects of calcium supplementation on bone mineral density at different sites

\begin{tabular}{lcccccc} 
Site & No of studies & No of participants & Effect size ${ }^{*}$ at end of trial & $\begin{array}{c}\text { No of } \\
\text { studies }\end{array}$ & $\begin{array}{c}\text { Eo of participants } \\
\text { Nect size* after supplement } \\
\text { ceased }\end{array}$ \\
\hline Femoral neck $\left(\mathrm{g} / \mathrm{cm}^{2}\right)$ & 10 & 1073 & $0.07(-0.05$ to 0.19$)$ & 5 & 617 & $0.10(-0.06$ to 0.26$)$ \\
\hline Lumbar spine $\left(\mathrm{g} / \mathrm{cm}^{2}\right)$ & 11 & 1164 & $0.08(-0.04$ to 0.20$)$ & 5 & 617 & $-0.01(-0.16$ to 0.17$)$ \\
\hline Total body $(\mathrm{g})$ & 9 & 953 & $0.14(0.01$ to 0.27$) \dagger$ & 1 & 96 & $0.00(-0.40$ to 0.40$) \ddagger$ \\
\hline Upper limb $\left(\mathrm{g} / \mathrm{cm}^{2}\right)$ & 12 & 1579 & $0.14(0.04$ to 0.24$) \dagger$ & 6 & 840
\end{tabular}

${ }^{*}$ Standardised mean difference ( $95 \%$ confidence interval); a standardised mean difference of 0.3 is regarded as small. ${ }^{22}$ $\dagger \mathrm{P}<0.05$.

$\ddagger$ Single study only. 


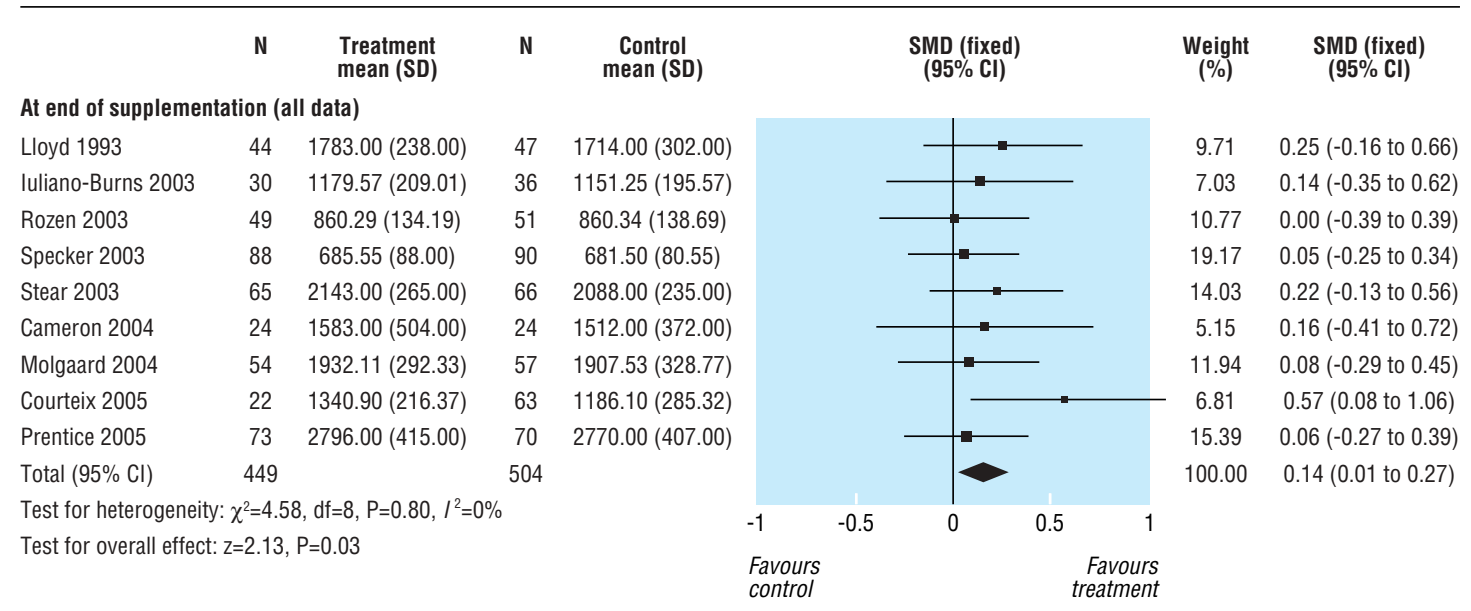

Fig 3 Effect of calcium supplementation on total body bone mineral content at the end of trial (SMD=standarised mean difference)

(standardised mean difference $0.07,95 \%$ confidence interval -0.05 to 0.19$)$ or at the lumbar spine $(0.08,-0.04$ to 0.20$)$ at end of trial. The effect at these sites after supplementation stopped was close to zero. The small increase in upper limb density $(0.14$, 0.04 to 0.24$)$ at end of trial persisted after supplementation stopped $(0.14,0.01$ to 0.28$)$ (fig 2). This effect is about the same as an increase in bone mineral density of $6.38 \mathrm{mg} / \mathrm{cm}^{2}$ or about 1.7 percentage point greater increase in supplemented groups over the course of supplementation and a $6.30 \mathrm{mg} / \mathrm{cm}^{2}$ or 1.7 percentage point greater increase after supplementation ceased. There was no significant heterogeneity of these results at any site $(\mathrm{P}=0.29$ to $\mathrm{P}>0.99)$. There was a small effect on total body bone mineral density $(0.14,0.01$ to 0.27$)$ at end of trial (fig 3$)$. The single study that reported total body density after supplementation stopped ${ }^{\mathrm{w} 31}$ showed no persistent effect $(0.0,-0.40$ to 0.40$)$.

Point estimates of treatment effects during supplementation were greater at all sites in females than males (table 3), though the sex difference was not significant. In the subgroup analyses, none of baseline calcium intake, ethnicity, physical activity, pubertal stage, type of supplementation (milk extract or other), duration of supplementation, and whether the calcium threshold was exceeded significantly modified the effects at any site (data not shown but available elsewhere ${ }^{16}$ ).

When we carried out sensitivity analysis omitting studies that used analysis of treatment received the results were not substantially altered. Omission of studies with imputed values reduced the effect at the upper limb after supplementation was stopped from a standardised mean difference of 0.14 (0.01 to 0.28$)$ to 0.10 ( -0.07 to 0.28 ), which was no longer significant, and marginally widened the confidence interval around the treatment effect for total body bone mineral density at the end of supplementation $(0.15,-0.01$ to 0.31$)$ without changing the point estimate. Sensitivity analyses did not otherwise substantially affect the results.

Funnel plots for each outcome did not indicate publication bias (data not shown). Adverse events were reported infrequently and were minor. ${ }^{16}$

\section{Discussion}

Calcium supplementation has little effect on bone mineral density. The only site where we found an effect was the upper limb and the effect was small, equivalent to about a 1.7 percentage point greater increase in bone mineral density in the supplemented group compared with the control group, which persisted after supplementation stopped. This effect was reduced and did not remain significant, however, when we excluded the studies with imputed outcomes, suggesting this result should be interpreted with caution. This small increase in upper limb bone mineral density is unlikely to result in a clinically important decrease in the risk of fracture. Importantly, we found no effects at other sites where fracture is common-namely, the femoral neck and lumbar spine.

Children with upper limb fractures have been reported to have $1-5 \%$ lower bone mineral density compared with controls at sites including the distal radius. ${ }^{9-11}$ Based on the decrease in odds ratio for wrist and forearm fractures observed for each SD increase in bone mineral density, ${ }^{11}$ the treatment effect we observed would result in about a 5\% decrease in the relative risk of fracture. If this were applied to the peak incidence of all frac-

Table 3 Effects of calcium supplementation on bone mineral density at different sites according to sex

\begin{tabular}{|c|c|c|c|c|c|c|}
\hline \multirow{2}{*}{ Site } & \multicolumn{3}{|c|}{ Male } & \multicolumn{3}{|c|}{ Female } \\
\hline & No of studies & No of participants & SMD* (95\% CI) & No of studies & No of participants & SMD* $(95 \% \mathrm{CI})$ \\
\hline \multicolumn{7}{|c|}{ At end of supplementation } \\
\hline Femoral neck $\left(\mathrm{g} / \mathrm{cm}^{2}\right)$ & 2 & 375 & $-0.05(-0.26$ to 0.15$)$ & 6 & 524 & $0.19(0.02$ to 0.37$) \dagger$ \\
\hline Lumbar spine $\left(\mathrm{g} / \mathrm{cm}^{2}\right)$ & 2 & 375 & $0.06(-0.14$ to 0.26$)$ & 7 & 615 & $0.11(-0.05$ to 0.27$)$ \\
\hline Total body (g) & 1 & 143 & $0.06(-0.27$ to 0.39$)$ & 7 & 632 & 0.18 (0.02 to 0.34$) \dagger$ \\
\hline Upper limb $\left(\mathrm{g} / \mathrm{cm}^{2}\right)$ & 3 & 459 & $0.03(-0.15$ to 0.21$)$ & 6 & 624 & $0.15(-0.01$ to 0.31$)$ \\
\hline \multicolumn{7}{|c|}{ After withdrawal of supplementation } \\
\hline Femoral neck $\left(\mathrm{g} / \mathrm{cm}^{2}\right)$ & 1 & 226 & $-0.03(-0.29$ to 0.23$)$ & 2 & 221 & $0.31(0.04$ to 0.58$) \dagger$ \\
\hline Lumbar spine $\left(\mathrm{g} / \mathrm{cm}^{2}\right)$ & 1 & 226 & $0.05(-0.22$ to 0.31$)$ & 2 & 221 & $0.04(-0.22$ to 0.31$)$ \\
\hline Upper limb $\left(\mathrm{g} / \mathrm{cm}^{2}\right)$ & 2 & 310 & $0.08 \quad(-0.32$ to 0.49$)$ & 2 & 200 & $0.30(0.02$ to 0.58$) \dagger$ \\
\hline
\end{tabular}

${ }^{*} \mathrm{SMD}=$ standardised mean difference; an SMD of 0.3 is regarded as small. ${ }^{22}$

†Significant at $\mathrm{P}<0.05$. 
tures in childhood (about 3\% a year in 15-19 year old boys and $1 \%$ in $10-14$ year old girls), ${ }^{23}$ the decrease in absolute risk would be at most $0.2 \%$ a year in boys and $0.1 \%$ in girls. Therefore, while it is possible that the small increase in bone mineral density from calcium supplementation could reduce the risk of fracture in childhood, the public health impact of this is likely to be small.

\section{Effect in adults}

Extrapolating these results to risk of fracture in adult life is problematic. Though the increase in bone mineral density at the upper limb persisted after supplementation stopped, the maximum length of follow-up after supplementation was only seven years, ${ }^{\mathrm{w} 1}$ and we do not know whether increases would persist into later life. In calcium supplement trials in postmenopausal women, the effect of supplementation on risk of fracture is at best small, ${ }^{24}{ }^{25}$ with increases in bone mineral density ranging from $1.13 \%$ to $2.05 \%$ depending on site. The increases at the lumbar spine and hip in the current review are substantially smaller than this and do not persist once supplementation stops. The upper limb increase we describe is similar to that in trials but its effect on risk of fracture remains uncertain. Any potential public health benefits of calcium supplementation in later life would probably be small.

Previous qualitative reviews of calcium supplementation trials in children reported that overall calcium supplementation seemed to have a modest favourable effect on bone outcomes at the end of the treatment period..$^{13-15}$ One of the key aims of the most recent review of observational studies and randomised controlled trials was to assess whether dairy products are better for promoting bone integrity than other forms of calcium supplementation. ${ }^{15}$ The authors concluded that the literature did not support recommendations for consumption of dairy products for bone health end points in children and young adults. They also called into question the public health importance of the modest benefits of high dose calcium supplementation (noted in nine out of 10 trials) and dairy calcium supplementation (noted in two out of three trials) on bone health in youth. Our quantitative systematic review confirms this conclusion. Our results also do not support the premise that any type of calcium supplementation is more effective than another.

There was little evidence of effect modification. The consistently greater effects seen in females compared with males, though not significant, suggest a sex difference in the response of bone mineral density and bone mineral content to calcium supplementation. The fact that subgroup analyses by duration of supplementation showed no differences in treatment effects regardless of duration suggests that there is no cumulative effect of calcium over longer periods of supplementation.

Calcium supplementation may reduce bone remodelling rather than or as well as increasing bone modelling, accounting for the transient benefit of supplementation seen in some studies. ${ }^{26}$ In this case, one would expect the difference between treatment effects in shorter versus longer studies to be small because as the duration of supplementation increased, the rate of increase in bone mineral density or bone mineral content, or both, would decrease. Our data are consistent with this. However, one would also expect that after supplementation stopped there would be a decrease in treatment effect. We observed this in our data for total body bone mineral content but not upper limb bone mineral density. The reason for this inconsistency between sites is not clear.

During supplementation, the magnitude of changes in bone density outcomes was similar whether the total calcium intake in the intervention arms of the studies did or did not exceed the

\section{What is already known on this topic}

Narrative reviews of individual clinical trials have shown that bone mineral density in children can be increased by calcium supplementation

\section{What this study adds}

Calcium supplementation in healthy children has no effect on bone density at the hip or lumbar spine

Supplementation has a small effect at the upper limb, but the resultant increase in bone density is unlikely to result in a clinically important decrease in risk of fracture

threshold of $1400 \mathrm{mg} /$ day estimated in the literature ${ }^{19}{ }^{20}$ below which skeletal accumulation varies with intake. While this observation is consistent with the concept of a calcium threshold, our data cannot confirm the level of the threshold but suggests that the threshold lies below the suggested level of $1400 \mathrm{mg} /$ day.

\section{Limitations}

No studies measured fractures as an outcome, adding to the difficulty of interpreting the overall significance of the results. We did not include trials in children with medical conditions or taking medications that might affect bone metabolism, so the results can not be extrapolated to children with such conditions. Areal bone mineral density may only partly correct for bone size, and adjustment of bone mineral content for bone area, weight, and height is desirable. ${ }^{27}$ Only three studies provided such size adjusted data ${ }^{\mathrm{w} 9 \mathrm{w} 29}$ w34 and so we did not include this outcome in the meta-analysis. Qualitatively, however, the outcomes of these studies were similar, whether they were analysed with bone mineral density or bone mineral content adjusted for size.

Few studies were performed in children with low baseline calcium intakes. There were limited numbers of studies in purely postpubertal and peripubertal children. Given that calcium accumulation in the skeleton accelerates during puberty, ${ }^{28}{ }^{29}$ the paucity of data in the peripubertal period is an important gap. Subgroup analysis by level of physical activity showed no effect modification, but there were only a few studies and results of one study with data that could not be included in this analysis suggested this can occur. Therefore, we cannot exclude that physical activity might modify the effect.

In conclusion, there is a small effect of calcium supplementation only at the upper limb, but the resultant increase in bone mineral density is unlikely to result in a clinically important decrease in risk of fracture. Our results provide only limited support for the use of calcium supplementation in healthy children as a public health intervention. More studies are required in children with low calcium intakes and in peripubertal children. Given the small treatment effects seen with calcium supplementation, however, it may be appropriate to explore possible alternative nutritional interventions, such as increasing vitamin D concentrations $^{3031}$ and intake of fruit and vegetables. ${ }^{32}$

This review has been published as a Cochrane Review (Winzenberg TM, Shaw K, Fryer J, Jones G. Calcium supplementation for improving bone mineral density in children. Cochrane Database Syst Rev 2006;(2):CD005119). We thank Louise Falzon for her assistance with the design and implementation of the search strategy for this protocol, Lara Maxwell for coordinating assistance with several parts of this review, George Wells for statistical advice, and Guangju Zhai for assistance with translations.

Contributors: TW, GJ, and KS designed the review protocol. TW and KS undertook screening of articles, data extraction, and quality assessment. TW and JF performed the statistical analyses, with input from GJ. All authors 


\section{Research}

contributed to drafting the manuscript and approved the final version. TW is guarantor.

Funding: TW received support from the Government of Tasmania through the Dick Buttfield Memorial Fellowship. GJ receives support through a National Health and Medical Research Council practitioner fellowship. Competing interests: None declared.

Ethical approval: Not required.

1 Jones G, Nguyen T, Sambrook PN, Kelly PJ, Gilbert C, Eisman JA. Symptomatic fracture incidence in elderly men and women: the Dubbo osteoporosis epidemiology study incidence in elderly men and wome
(DOES). Osteoporos Int 1994;4:277-82.

2 Cooley H, Jones G. A population-based study of fracture incidence in southern Tasmania: lifetime fracture risk and evidence for geographic variations within the same country. Osteoporos Int 2001;12:124-30.

3 Woolf AD, Pfleger B. Burden of major musculoskeletal conditions. Bull World Health Organ 2003;81:646-56.

4 Marshall D, Johnell O, Wedel H. Meta-analysis of how well measures of bone mineral density predict occurrence of osteoporotic fractures. BMJ 1996;312:1254-9.

5 Bailey DA, McKay HA, Mirwald RL, Crocker PR, Faulkner RA. A six-year longitudinal study of the relationship of physical activity to bone mineral accrual in growing children: the university of Saskatchewan bone mineral accrual study.J Bone Miner Res $1999 ; 14: 1672-9$

6 Hansen MA, Overgaard K, Riis BJ, Christiansen C. Role of peak bone mass and bone loss in postmenopausal osteoporosis: 12 year study. BMJ 1991;303:961-4.

7 Riis BJ, Hansen MA, Jensen AM, Overgaard K, Christiansen C. Low bone mass and fast rate of bone loss at menopause: equal risk factors for future fracture: a 15-year follow-up study. Bone 1996;19:9-12.

8 Javaid MK, Cooper C. Prenatal and childhood influences on osteoporosis. Best Pract Res Clin Endocrinol Metab 2002;16:349-67.

9 Goulding A, Cannan R, Williams SM, Gold EJ, Taylor RW, Lewis-Barned NJ. Bone mineral density in girls with forearm fractures.J Bone Miner Res 1998;13:143-8.

10 Goulding A, Jones IE, Taylor RW, Williams SM, Manning PJ. Bone mineral density and body composition in boys with distal forearm fractures: a dual-energy $\mathrm{x}$-ray absorptiometry study. J Pediatr 2001;139:509-15.

$11 \mathrm{Ma}$, Jones $\mathrm{G}$. The association between bone mineral density, metacarpal morphometry, and upper limb fractures in children: a population-based case-control study. J Clin Endocrinol Metab 2003;88:1486-91.

12 Chan GM, Hoffman K, McMurry M. Effects of dairy products on bone and body composition in pubertal girls. J Pediatr 1995;126:551-6.

13 French SA, Fulkerson JA, Story M. Increasing weight-bearing physical activity and calcium intake for bone mass growth in children and adolescents: a review of intervention trials. Prev Med 2000;31:722-31.

14 Wosje KS, Specker BL. Role of calcium in bone health during childhood. Nutr Rev 2000;58:253-68.

15 Lanou AJ, Berkow SE, Barnard ND. Calcium, dairy products, and bone health in children and young adults: a reevaluation of the evidence. Pediatrics 2005;115:736-43

16 Winzenberg TM, Shaw K, Fryer J, Jones G. Calcium supplementation for improving bone mineral density in children. Cochrane Database Syst Rev 2006;(2):CD005119.
17 Jadad AR, Moore RA, Carroll D, Jenkinson C, Reynolds DJ, Gavaghan DJ, et al. Assessing the quality of reports of randomized clinical trials: is blinding necessary? Control Clin Trials 1996;17:1-12.

18 Juni P, Altman DG, Egger M. Systematic reviews in health care: assessing the quality of controlled clinical trials. BMJ 2001;323:42-6.

19 Matkovic V, Heaney RP. Calcium balance during human growth: evidence for threshold behavior. Am J Clin Nutr 1992;55:992-6.

20 Jackman LA, Millane SS, Martin BR, Wood OB, McCabe GP, Peacock M, et al. Calcium retention in relation to calcium intake and postmenarcheal age in adolescent females. Am J Clin Nutr 1997;66:327-333.

21 Alderson P, Green S. Additional module 1: meta-analysis of continuous data. In: Alderson P, Green S, eds. Cochrane collaboration open learning material for reviewers. 2002:1.1.

22 Cohen J. Statistical power analysis for the behavioral sciences. Hillside, NJ: Lawrence Cohen J. Statisticil
Erlbaum, 1988.

23 Jones G, Cooley HM. Symptomatic fracture incidence in those under 50 years of age in southern Tasmania. J Paediatr Child Health 2002;38:278-83.

24 Shea B, Wells G, Cranney A, Zytaruk N, Robinson V, Griffith L, et al. Calcium supplementation on bone loss in postmenopausal women. Cochrane Database Syst Rev 2004;(1):CD004526.

25 Jackson RD, LaCroix AZ, Gass M, Wallace RB, Robbins J, Lewis CE, et al. Calcium plus vitamin D supplementation and the risk of fractures. N Engl J Med 2006;354:669-83.

26 Heaney RP. The bone remodeling transient: interpreting interventions involving bonerelated nutrients. Nutr Rev 2001;59:327-34.

27 Prentice A, Parsons TJ, Cole TJ. Uncritical use of bone mineral density in absorptiometry may lead to size-related artifacts in the identification of bone mineral etry may lead to size-related artifacts in
determinants. Am J Clin Nutr 1994;60:837-42.

28 Bonjour JP, Theintz G, Buchs B, Slosman D, Rizzoli R. Critical years and stages of puberty for spinal and femoral bone mass accumulation during adolescence. J Clin Endocrinol Metab 1991;73:555-63.

29 Abrams SA, O'Brien KO, Stuff JE. Changes in calcium kinetics associated with menarche. J Clin Endocrinol Metab 1996;81:2017-20.

30 Moyer-Mileur LJ, Xie B, Ball SD, Pratt T. Bone mass and density response to a 12-month trial of calcium and vitamin D supplement in preadolescent girls. $J$ Musculoskelet Neuronal Interact 2003;3:63-70.

31 Zhu K, Greenfield H, Zhang Q, Ma G, Zhang Z, Hu X, et al. Bone mineral accretion and growth in Chinese adolescent girls following the withdrawal of school milk intervention: preliminary results after two years. Asia Pac J Clin Nutr 2004;13:S83.

32 Jones G, Riley MD, Whiting S. Association between urinary potassium, urinary sodium, current diet, and bone density in prepubertal children. Am J Clin Nutr 2001;73:839-44. (Accepted 2 August 2006)

doi $10.1136 /$ bmj. .38950 .561400 .55

Menzies Research Institute, Private Bag 23, Hobart, Tas 7001, Australia

Tania Winzenberg musculoskeletal epidemiologist

Jayne Fryer statistics fellow

Graeme Jones head, musculoskeletal unit

Department of Health and Human Services, Hobart, Tas 7000, Australia

Kelly Shaw specialist medical advisor

Correspondence to: T Winzenberg tania.winzenberg@utas.edu.au 